\title{
Commentary on "Effects of gonadotropin-releasing hormone agonist treatment on final adult height in boys with idiopathic central precocious puberty"
}

\section{Chong Kun Cheon}

Department of Pediatrics, Pusan National University Children's Hospital, Yangsan, Korea
See the article "Effects of gonadotropin-releasing hormone agonist treatment on final adult height in boys with idiopathic central precocious puberty" via https://doi. org/10.6065/apem.2040268.134.

Address for correspondence: Chong Kun Cheon

Division of Pediatric Endocrinology, Department of Pediatrics, Pusan National University Children's Hospital, Pusan National University School of Medicine, Geumo-ro 20, Yangsan 50612, Korea

Email: chongkun@pusan.ac.kr

https://orcid.org/0000-0002-86095826
Precocious puberty has become an important social issue worldwide. In particular, precocious puberty affects various physical and mental health, and among them, the impact on final adult height (FAH) will be the most interesting part. Gonadotropin-releasing hormone agonist (GnRHa) treatment in patients with central precocious puberty (CPP) has long been used as a standardized treatment, and studies on the effect on FAH have also been reported domestically and internationally.

A large-scale meta-analysis study reported in 2014 suggested that GnRHa treatment has a positive effect on FAH in girls with CPP. ${ }^{1)}$ Subsequently, in 2019, a meta-analysis study reported that GnRHa treatment plus growth hormone had the highest probability of being the optimal therapy for improving FAH in girls with $\mathrm{CPP}^{2)}$ In a recent study of 84 Korean girls with CPP, FAH was significantly higher than the initially predicted adult height (PAH) in girls with CPP treated with GnRHa. ${ }^{3)}$

When looking at the factors affecting FAH in girls with CPP having GnRHa treatment, Cho et al. ${ }^{4)}$ suggested that FAH is associated with significant factors including target height (TH), height at the start of GnRHa treatment, height standard deviation score (SDS), PAH, and height SDS at the end of treatment. Guaraldi et al. ${ }^{5}$ reported that FAH is related to the influencing factors such as young chronological age at the time of diagnosis, height SDS at the start and end of treatment, and duration of treatment. In a study of 166 girls diagnosed with CPP, Kim et al. ${ }^{6}$ suggested that younger age, higher PAH at the start of treatment, and a greater increase in PAH SDS during the first year of GnRHa treatment positively affect FAH.

However, studies of boys with CPP on the effectiveness of GnRHa treatment are still insufficient than girls with CPP in terms of sample size or the number of published papers. The few studies on the influencing factors of FAH following GnRHa treatment in 12 boys reported $\mathrm{TH}$ and height at the end of GnRHa as important predictive factors.

In this work, the authors investigated the effect of GnRHa treatment on FAH as well as significant factors of FAH in a retrospective study of 18 boys with CPP using the BayleyPinneau (BP) method. As is well known, attention should be paid to predicting FAH in practice, as predictions using BP methods during GnRHa treatment or end of treatment can overestimate FAH. Notably, the authors suggested that PAH-calculated with advanced at the end of treatment is associated with FAH. ${ }^{8)}$ Also, GnRHa treatment made it possible to reach the FAH to the range of TH in boys with CPP without losing their growth potential. It would be suggested that interpretation of the factor affecting growth to FAH is more appropriate by restoring growth potential after therapy in individuals with CPP rather than the FAH itself.

The limitation of this study is that it is also a short follow-up study of a small number. Further investigation is required to determine the essential factors that maximize potential linear growth and estimate the effect of GnRHa treatment on FAH in boys with CPP with a long-term multicenter study.

\section{Conflict of interest}

No potential conflict of interest relevant to this article was reported. 


\section{References}

1. Li P, Li Y, Yang CL. Gonadotropin releasing hormone agonist treatment to increase final stature in children with precocious puberty: a meta-analysis. Medicine (Baltimore) 2014;93:e260.

2. Gu Q, Luo Y, Ye J, Shen X. Comparative efficacy and safety of three current clinical treatments for girls with central precocious puberty: a network meta-analysis. Endocr Pract 2019;25:717-28.

3. Lee HS, Yoon JS, Park KJ, Hwang JS. Increased final adult height by gonadotropin-releasing hormone agonist in girls with idiopathic central precocious puberty. PLoS One 2018;13:e0201906.

4. Cho AY, Ko SY, Lee JH, Kim EY. Relationship between final adult height and birth weight after gonadotropin-releasing hormone agonist treatment in girls with central precocious puberty. Ann Pediatr Endocrinol Metab 2020;25:24-30.

5. Guaraldi F, Beccuti G, Gori D, Ghizzoni L. Management of endocrine disease: long term outcomes of the treatment of central precocious puberty. Eur J Endocrinol 2016;174:R7987.

6. Kim MS, Koh HJ, Lee GY, Kang DH, Kim SY. Comparing adult height gain and menarcheal age between girls with central precocious puberty treated with gonadotropinreleasing hormone agonist alone and those treated with combined growth hormone therapy. Ann Pediatr Endocrinol Metab 2019;24:116-23.

7. Rizzo V, De Sanctis V, Corrias A, Fortini M, Galluzzi F, Bertelloni $S$, et al. Factors influencing final/near-final height in 12 boys with central precocious puberty treated with gonadotrophin-releasing hormone agonists. Italian Study Group of Physiopathology of Puberty. J Pediatr Endocrinol Metab 2000;13 Suppl 1:781-6.

8. Cho AY, Ko SY, Lee JH, Kim EY. Effects of gonadotropinreleasing hormone agonist treatment on final adult height in boys with idiopathic central precocious puberty. Ann Pediatr Endocrinol Metab 2021;26:259-65. 